\title{
Synthesis of CoFe 204 /BiOl Nanocomposite: Effects on Staphylococcus aureus, Escherichia coli, Pseudomonas Aeruginosa and Bacillus Cereus
}

Davood Gheidari ( $\nabla$ davoodgheidari@phd.guilan.ac.ir)

University of Guilan

Morteza Mehrdad

University of Guilan

Saloomeh Maleki

University of Shahrood

Samanesadat Hosseini

Shahid Beheshti University of Medical Science

Research Article

Keywords: Biological activity of CFO/BiOl, Nanocomposite

Posted Date: August 31st, 2021

DOI: https://doi.org/10.21203/rs.3.rs-842251/v1

License: (c) (i) This work is licensed under a Creative Commons Attribution 4.0 International License.

Read Full License 


\section{Abstract}

With the increase of general knowledge and the advancement of science and technology, antibacterial substances were used more than antibiotics. In our current study, the antibacterial virtues of $\mathrm{CFO} / \mathrm{BiOI}$ nanocomposite were investigated due to its high importance on Staphylococcus aureus, Escherichia coli, Pseudomonas aeruginosa and Bacillus cereus. MIC, MBC, Disk Diffusion and IC50 tests Cefalotin (CF), Amoxicillin (AMX), Gentamicin (GM), Trimethoprim-sulphamethoxazole (SXT) and Ceftriaxone (CRO) antibiotics in concentration $30 \mathrm{~W}, 10 \mathrm{i}, 10 \mathrm{t}, 25 \mathrm{~h}$ and 30 were used to find the antibacterial properties of the synthesized nanocomposite, respectively. For the synthesis of nanocomposites polyethylene glycol (PEG) and sulfonic acid was used as a solvent. It is noteworthy that the synthesis was performed by heat dissolution method without the presence of surfactant. Also, various techniques such as X-Ray Diffraction(XRD), Scanning Electron Microscope (SEM), High resolution mapping and Energy Dispersive X-ray spectroscopy (EDAX) have been used to determine the properties of produced nanocomposites. SEM test results showed that the formed nanoparticles were globular and their size was limited area of 22 to $34 \mathrm{~nm}$. The results showed CFO / BiOI nanocomposite exhibits strong significant biological activity against Bacillus cereus. The results of MBC (Minimum Bactericidal Concentration) and MIC (Minimum Inhibition Concentration) tests for $\mathrm{CFO} / \mathrm{BiO}$ nanocomposites on bacteria were examined in the range of $0.12-0.48 \mathrm{mg} / \mathrm{ml}$ and 0.06 to $0.24 \mathrm{mg} / \mathrm{ml}$ respectively. According to the results, the minimum IC50 value was determined at a concentration of $0.061 \mathrm{mg} / \mathrm{ml}$. On the other hand, the most resisting and susceptible bacteria in this method were Pseudomonas aeruginosa and Bacillus cereus, respectively. These findings are identical to those of a prior study on $\mathrm{CoFe}_{2} \mathrm{O}_{4}$ nanoparticles antibacterial properties. MBC of the nanocomposites, $50 \mu \mathrm{l}$ from all the tubes that showed no obvious bacterial growth were distributed on $\mathrm{BHI}$ agar plates and incubated for $24 \mathrm{~h}$ at $37^{\circ} \mathrm{C}$. The MBC endpoint is defined as the lowest concentration which killed $98 \%$ of the bacterial population.

\section{Introduction}

Nanomaterials are receiving growing interest for his or her promise as engineering and biomedical miracles. In fact, nanomaterials help overcome length restrictions and have the potential to change the scientific landscape. Magnetic nanoparticles (MNPs) are a subset of nanomaterials that are widely used in biomedical applications. Cobalt ferrite $\left(\mathrm{CoFe}_{2} \mathrm{O}_{4}\right)$ MNPs are widely used in Imaging (MRI), cancer treatment, fluids, drug delivery, hyperthermia [1,2] diagnosis [2,3] and in electronic devices due to high permeability, by force, medium magnetization finding, high saturation magnification [4]. Physiochemical stability [5] and antibacterial properties.

$\mathrm{BiOl}$ is a $\mathrm{V}-\mathrm{VI}-\mathrm{VII}$ ternary compound with an open layer structure made up of $\left[\mathrm{Bi}_{2} \mathrm{O}_{2}\right]$ slabs interrupted by binary I atom slabs [6]. BiOl has been selected as one of the most important and new semiconductors for visible light catalysts due to its high structural diversity, easy synthesis and narrow bandwidth $(1.78 \mathrm{eV})$ [7-8]. BiOI magnetic nanocomposites have been extensively studied due to their convenient assembly by an exterior magnetic field [9]. One of the methods of synthesis of BiOl magnetic composites is the 
deposition of magnetic nanoparticles on the structure of $\mathrm{BiOl}$ by exothermic methods. Recently, $\mathrm{Fe}_{3} \mathrm{O}_{4}$ core / shell nanoparticles with BiOl coating have been reported by thermal and sequential ion layer ion adsorption and reaction (SILAR) [10]. These BiOI nano magnetic powders, however, have a restricted application due to they are readily disposed of and collected. Therefore, the search for suitable carriers for $\mathrm{BiOl}$ immobilization is desirable for the fabrication of new $\mathrm{BiOl}$ magnetic nanostructures. $\mathrm{CFO} / \mathrm{BiOI}$ nanocomposite has recently been found to have extremely significant biological activity against Bacillus cereus.

In our current study, a $\mathrm{CoFe} \mathrm{O}_{4} / \mathrm{BiOl}$ (CFO/BiOl) composite nanofiber with high magnetic strength and visible light photocatalytic performance for color degradation was introduced. The synthesis of $\mathrm{CFO} / \mathrm{BiOI}$ nanofibers was obtained by heating and growing $\mathrm{CFO} / \mathrm{BiOl}$ on the surface of $\mathrm{CoFe}_{2} \mathrm{O}_{4}$ fiber. The important point is that the strong magnetic response of $\mathrm{CoFe}_{2} \mathrm{O}_{4}$ can be used to estimate the need for $\mathrm{BiOl}$ deposition and magnetic separation. First, inorganic $\mathrm{CoFe}_{2} \mathrm{O}_{4}$ has better thermal register than organic fiber support [11]. Second, the structure of magnetic fibers is easily collectible and the accumulation of $\mathrm{BiOl}$ on the surface of the fibers is not easy $[12,13]$. Furthermore, pure BiOl with a strong response to visible light for the photocatalysis process can be applied to the fiber surface using several synthetic techniques without attaching to metallic nanoparticles.

\section{Synthesis Of Bioi}

To begin, $10 \mathrm{~mL}$ ethylene glycol was mixed with $1 / 51 \mathrm{~g}$ bismuth trinitrate and swirled for 45 minutes at high speed until thoroughly dispersed and simultaneously $0.5 \mathrm{~g}$ of potassium iodide was dissolved in 5 $\mathrm{ml}$ of distilled water. Using an injection syringe, potassium iodide solution was injected dropwise to the original solution under vigorous agitation. The reaction was continued for 2 hours after mixing the initial solution with potassium iodide solution, and the resultant red solution was transferred to a steel autoclave. The autoclave was heated for 12 hours at $180^{\circ} \mathrm{C}$, then cooled to ambient temperature before the precipitate was centrifuged and filtered through a $0.22 \mu \mathrm{m}$ millipurper membrane. To remove possible impurities, the product was washed 3 times with water, distilled twice and ethanol, then dried at $75^{\circ} \mathrm{C}$ oven for 6 hours $[14,15]$.

\section{Synthesis Of Cofe2o4}

In the present study, a heating bribe was used to synthesize $\mathrm{CoFe}_{2} \mathrm{O}_{4}$ magnetic nanoparticles. In this method, we dissolve 2 grams of PEG in $30 \mathrm{ml}$ of diameter water, the resulting solution is eaten by a magnetic stirrer for 10 minutes. To complete the process, a certain amount of dehydrating iron (III) chloride, cobalt chloride, sodium acetate and sulfonic acid were added to the solution and stirred for about 8 hours with a magnetic stirrer to homogenize the mixture. The use of sulfonic acid makes it easier to reuse nanoparticles. The final solution was dried for 15 hours at $190^{\circ} \mathrm{C}$ in a furnace. To remove impurities from the precipitate, it is rinsed several times with $96 \%$ ethanol for further purification. The final 
precipitate was thoroughly dried in a free medium for one day before being heated at $450^{\circ} \mathrm{C}$ for 2 hours to yield $\mathrm{CoFe}_{2} \mathrm{O}_{4}$ magnetic nanoparticles [16].

\section{Synthesis Of Cfo/bioi Hybrid Nanofiber By Solvothermal Method}

As mentioned in the previous section, the $\mathrm{BiOl}$ thermal growth method on the $\mathrm{CoFe}_{2} \mathrm{O}_{4}$ fiber surface was used to synthesize $\mathrm{CFO} / \mathrm{BiOI}$ nanofiber. For the synthesis of $\mathrm{CFO} / \mathrm{BiOl}$ nanofibers, equal concentrations of bismuth nitrate and potassium iodide were dissolved in $40 \mathrm{ml}$ of ethylene glycol. Then $30 \mathrm{mg}$ of $\mathrm{CoFe}_{2} \mathrm{O}_{4}$ nanofibers were prepared. The resulting mixture was transferred to an autoclave of $50 \mathrm{ml}$ and heated at $160^{\circ} \mathrm{C}$ for 10 hours. After 10 hours to reach free space temperature was placed in the environment. The final product was washed several times with ethanol to remove impurities [17].

\section{Bacterial Strains And Culture Conditions}

The bacterial strains utilized to investigate BiOl's biological activity and CoFe204/BiOl have been provided from the Persian Type Culture Collection. The strains Pseudomonas aeruginosa, Bacillus cereus, Staphylococcus aureus and Escherichia coli were cultured on appropriate nutrient media. The standard bacterial inoculum was made using a spectrophotometer calibrated to $620 \mathrm{~nm}$ and $0.5 \mathrm{McF}$ arland's standard $(1.5108 \mathrm{CFU} / \mathrm{ml})$ and cultured for 24 hours at $37^{\circ} \mathrm{C}$.

The sensitivity of each strain to nanoparticles were assessed with the Kirby-Bauer agar disk diffusion method. For this test, $100 \mu$ of each above bacterial inoculum streaked on Mueller Hinton Agar surface by the swab, the impregnated discs with various nanoparticles were then placed on the agar plate's surface. The blank disc with no nanoparticle and antibiotic discs including Cefalotin (CF), Amoxicillin (AMX), Gentamicin (GM), Trimethoprim-Sulphamethoxazole (SXT) and Ceftriaxone (CRO) were utilized as negative and positive control, respectively. Finally, the heated plates were incubated for 24 hours at $37^{\circ} \mathrm{C}$ under white light at 18 volts at a distance of $33 \mathrm{~cm}$, and the breadth of the growth inhibition zone was determined.

For Minimum Inhibitory Concentration (MIC), the standard broth dilution procedure was utilized to assay the biological activity of nanoparticles by evaluating the visible growth of microorganisms in the agar broth. Serial two-fold dilutions of nanoparticles in concentrations ranging from $0.03,0.06,0.12,0.24$ and $0.48 \mathrm{mg} / \mathrm{ml}$ with adjusted bacterial concentration $\left(1.5 \times 10^{8} \mathrm{CFU} / \mathrm{ml}, 0.5 \mathrm{McF}\right.$ arland's standard) were used to determine MIC in $\mathrm{BHI}$ broth. The control contained only inoculated broth and medium contained only nanoparticles incubated for $24 \mathrm{~h}$ at $37^{\circ} \mathrm{C}$. The MIC endpoint is the lowest concentration of nanoparticles where no visible growth is seen in the tubes. The visual turbidity of the tubes was noted, both before and after incubation to confirm the MIC value. For Minimum Bactericidal Concentration (MBC) of the nanoparticles, $50 \mu \mathrm{l}$ from all the tubes which showed no visible bacterial growth were distributed on $\mathrm{BH}$ agar plates and incubated for $24 \mathrm{~h}$ at $37^{\circ} \mathrm{C}$. The lowest concentration that killed $99 \%$ of the bacterial population is termed as MBC endpoint. 


\section{Result And Discussion}

According Table $1 \mathrm{~S}$. aureus showed higher sensitivity to both nanoparticles than other strains. As well as, a moderate sensitivity was also observed for the strains $P$. aeruginosa and $E$. coli. The MIC and MBC endpoints for strains aeruginosa. aureus and $E$. coli were observed to be the same and 0.24 and 0.48 $\mathrm{mg} / \mathrm{ml}$ respectively (Table 2). The $\mathrm{BiOl}$ and $\mathrm{CFO} / \mathrm{BiOl}$ can have inhibitory and lethal effects on $B$. cereus in lower amounts. In general, $\mathrm{BiOI}$ alone and in combination with $\mathrm{CFO}$ (CFO/BiOI) show the same antimicrobial effect.

\subsection{Analysis of XRD}

Using X'Pert Pro system from the Panalytical company, X-ray diffraction patterns of $\mathrm{CoFe}_{2} \mathrm{O}_{4} \mathrm{BIOI}$ and $\mathrm{CFO} / \mathrm{BiO}$ nanofiber were reported under the following conditions: $40 \mathrm{~mA}, 40 \mathrm{kV}$, step size: 0.02, and timer per step $1 \mathrm{~s} /$ step. The XRD analysis of $\mathrm{CoFe}_{2} \mathrm{O}_{4} \mathrm{NPs}$ is displayed in Figure 1. As seen in Figure 1a, the peaks at $2 \theta$ values of $30.19 \circ, 35.53 \circ, 43.17 \circ, 53.54 \circ, 57.087 \circ, 62.68 \circ$ and $74.20 \circ$ were respectively correspond to the (220), (311), (222), (400), (422), (511) and (440) planes with a cubic spinel structure (EX PAPER). In Figure 1b, the peaks observed of BiOl in the $2 \theta$ angles of 29.71॰, $31.75 \circ, 37.26 \circ, 39.30$, $45.51 \circ, 46.62 \circ$ and 51.51。 related to (312), (004), (204), (020), (604), (316) and (912) reflections plane.

\subsection{Analysis of FE-SEM}

The Field Emission Scanning Electron Microscope (FE-SEM) is similar to the SEM microscope and generally retains the basic characteristics of SEM such as resolution, depth of field, signal diversity, and processing, as well, there is no need to conduct the sample in FE-SEM and it is possible to create a liquid injection system and it is also possible to observe the dynamics of the gas-liquid-solid system.

FE-SEM tests of sample BiOI and CFO/BiOI were performed using the device according SIGMA VP model system from ZEISS Company and one of the important results obtained from FE-SEM test was the uniform distribution of spherical nanoparticles. Figure2 displays the morphology of FE-SEM and also showed that the particle size is in nanometers.

The results of SEM test showed that particle BiOI had a size of 76-34 and particle CFO/BiOI had a particle size of 51-51 nm, which corresponds to the size given in the XRD test. The result of SEM test showed nonuniform accumulation due to magnetic force in the morphology of CFO / BiOI particles.

EDAX test was utilized to determine the elements present on the surface of $\mathrm{CFO} / \mathrm{BiO}$ nanocomposite. EDX analysis indicated pure $\mathrm{CoFe}_{2} \mathrm{O}_{4} / \mathrm{BiOI}$ nanoparticles formation; Figure $3 a$ depicts the three elements that make up synthesized $\mathrm{BiOI}$, whereas Figure $3 \mathbf{b}$ depicts the purity of $\mathrm{CoFe}_{2} \mathrm{O}_{4} / \mathrm{BiOl}$ nanoparticles, as well as their constituents. Figure 4 demonstrates the existence of additional elements $\mathrm{O}, \mathrm{Fe}, \mathrm{Co}, \mathrm{Bi}$, and I in the nanocomposite surface, which are precisely the same elements found in the EDAX test, and no peak was seen for another element, according to the corresponding elemental mappings results. 
The cell survival MTT assay utilizing ELISA READER method was used to evaluate the cytotoxicity of the synthesized nanocomposite and in order to do this, they incubated $0.06 \mathrm{mg} / \mathrm{ml}$ and $0.48 \mathrm{mg} / \mathrm{ml}$ for 24 hours. As mentioned in the previous article, the same goes for this synthesis, the analysis indicated a survival rate of more than $50 \%$ for the maximum concentration of $0.06 \mathrm{mg} / \mathrm{ml}$ and the obtained data show that the nanocomposite synthesized by solvothermal method has the ability to kill bacteria and of course, this means that the ability is concentration dependent and we see more cell death with increasing concentration. In addition, based on the results, the IC50 value was determined to be $0.06 \mathrm{mg} / \mathrm{ml}$. Energy Dispersive X-ray (EDAX) and corresponding elemental mappings test results were exactly equal and showed that the surface elements present on the surface of $\mathrm{CFO} / \mathrm{BiOI}$ nanocomposite include $\mathrm{O}, \mathrm{Fe}, \mathrm{Co}$, $\mathrm{Bi}, \mathrm{l}$.

Table 1. Bacterial growth inhibition zone $(\mathrm{mm})$ based on the nanoparticle concentration

\begin{tabular}{|llllllll|}
\hline Bacteria & \multicolumn{2}{l}{ Inhibition Zone $(\mathbf{m m})$} & & & & \\
& BiOl (0.48 mg) & CFO/BiOI (0.48) & SXT & GM & AMX & CRO & CF \\
\hline Bacillus cereus & 18 & 18 & 25 & 25 & $\mathrm{R}$ & 22 & $\mathrm{R}$ \\
\hline Pseudomonas aeruginosa & 15 & 15 & $\mathrm{R}$ & & & & \\
& & & & $\mathrm{R}$ & $\mathrm{R}$ & 16 & $\mathrm{R}$ \\
\hline Escherichia coli & 17 & 17 & 32 & $\mathrm{R}$ & $\mathrm{R}$ & 32 & $\mathrm{R}$ \\
\hline Staphylococcus aureus & 27 & 27 & 37 & & & & \\
& & & & 37 & $\mathrm{R}$ & $\mathrm{R}$ & $\mathrm{R}$ \\
\hline
\end{tabular}

Abbreviations: $\mathbf{R}$, resistant

Table 2. MIC and MBC CFO/BiOI, BiOI nanoparticles

\begin{tabular}{|lll|}
\hline Bacteria & $\mathrm{MBC}(\mathrm{mg} / \mathrm{ml})$ & $\mathrm{MIC}(\mathrm{mg} / \mathrm{ml})$ \\
\hline Escherichia coli & 0.48 & 0.24 \\
\hline Staphylococcus aureus & 0.48 & 0.24 \\
\hline Pseudomonas aeruginosa & 0.48 & 0.24 \\
\hline Bacillus cereus & 0.12 & 0.06 \\
\hline
\end{tabular}

\section{Conclusion}

In the present study, $\mathrm{CFO} / \mathrm{BiOI}$ nanocomposites were synthesized using the solvothermal method. The properties of $\mathrm{CFO} / \mathrm{BiO}$ nanocomposites were investigated by using various XRD, SEM, High Resolution Mapping and EDAX. Furthermore, the MIC, MBC and biological activity of CFO/BiOI nanocomposite against Gram-positive (Staphylococcus aureus and Bacillus cereus) and Gram-negative (Pseudomonas 
aeruginosa and Escherichia coli) bacteria were tested under visible light with different weight nits of $\mathrm{CFO} / \mathrm{BiOI}$. The result of this study is a decrease in the susceptibility of Staphylococcus aureus from nanocomposites compared to similar studies, which indicates an increase in the antibacterial ability of $\mathrm{BiOI}$ nanocomposites. Based on the results, the IC50 value of $\mathrm{CFO} / \mathrm{BiOI}$ nanocomposite was determined to be $0.06 \mathrm{mg} / \mathrm{ml}$ and by confirming other antibacterial tests, it showed a suitable concentration to inhibit $50 \%$ of bacterial growth. According to the results of the antibacterial test, MBC of the nanocomposites, $50 \mu \mathrm{l}$ from all the tubes which showed no visible bacterial growth were distributed on $\mathrm{BHI}$ agar plates and incubated for $24 \mathrm{~h}$ at $37^{\circ} \mathrm{C}$. The lowest concentration that killed $98 \%$ of the bacterial population is termed as MBC endpoint. So, the nanoparticles showed good potency against all of the microorganisms which were used in this study.

\section{References}

1. Sincai, M., Ganga, D., Bica, D. \& Vekas, L. The antitumor effect of locoregional magnetic cobalt ferrite in dog mammary adenocarcinoma. J. Magn. Magn Mater, 225, 235-240 https://doi.org/10.1016/S0304-8853(00)01263-4 (2001).

2. Hong, N. H. et al. Ferrite nanoparticles for future heart diagnostics. Appl. Phys. A, 112, 323-327 https://doi.org/10.1007/s00339-013-7573-y (2013).

3. Sanpo, N., Berndt, C. C., Wen, C. \& Wang, J. Transition metal-substituted cobalt ferrite nanoparticles for biomedical applications. Acta. Biomater, 9, 5830-5837 https://doi.org/10.1016/j.actbio.2012.10.037 (2013).

4. Li, Y., Zhang, W., Niu, J. \& Chen, Y. Mechanism of photogenerated reactive oxygen species and correlation with the antibacterial properties of engineered metal-oxide nanoparticles., 6, 5164-5173 https://doi.org/10.1021/nn300934k (2012).

5. Marmorato, P. et al. Cellular distribution and degradation of cobalt ferrite nanoparticles in Balb/3T3 mouse fibroblasts. Toxicol. Lett, 207, 128-136 https://doi.org/10.1016/j.toxlet.2011.08.026 (2011).

6. Dong, R. et al. Visible-light-driven BiOI Based janus micromotor in pure water. J. Am. Chem. Soc, 139, 1722-1725 https://doi.org/10.1021/jacs.6b09863 (2017).

7. Long, B. et al. Carbon Dots Sensitized BiOI with Dominant $\{001\}$ Facets for Superior Photocatalytic Performance. Ind. Eng. Chem. Res, 54, 12788-12794 https://doi.org/10.1021/acs.iecr.5b02780 (2015).

8. Sultana, S., Mansingh, S. \& Parida, K. M. Facile synthesis of $\mathrm{CeO} 2$ nanosheets decorated upon BiOI microplate: a surface xxygen vacancy promoted Z-Scheme-based 2D-2D nanocomposite photocatalyst with enhanced photocatalytic activity. J. Phys. Chem. C, 122, 808-819 https://doi.org/10.1021/acs.jpcc.7b08534 (2018).

9. Mehraj, O., Pirzada, B. M., Mir, N. A., Khan, M. Z. \& Sabir, S. A highly effıcient visiblelight driven novel p-n junction Fe203/BiOl photocatalyst: Surface decoration of BiOI nanosheets with Fe2O3 nanoparticles. Appl. Surf. Sci, 387, 642-651 https://doi.org/10.1016/j.apsusc.2016.06.166 (2016). 
10. Zheng, L., Wang, S., Zhao, L. \& Zhao, S. Core/shell Fe304/BiOI nanoparticles with high photocatalytic activity and stability. J. Nanopart. Res, 18, 318 https://doi.org/10.1007/s11051-016-3636-2 (2016).

11. Sui, C. et al. Different coating on electrospun nanofiber via layer-by-layer self-assembly for their photocatalytic activities. Colloids Surf A, 529, 425-433 https://doi.org/10.1016/j.colsurfa.2017.06.030 (2017).

12. Ma, W. et al. Facile synthesis of the magnetic BiOCl/ZnFe2O4 heterostructures with enhanced photocatalytic activity under visible-light irradiation. Colloids Surf $A, 508,135-141$ (2016).

13. Zhu, D., Liu, S., Chen, M., Zhang, J. \& Wang, X. Flower-like-flake Fe3O4/g-C3N4 nanocomposite: Facile synthesis, characterization, and enhanced photocatalytic performance. Colloids Surf A, 537, 372382 https://doi.org/10.1016/j.colsurfa.2017.10.053 (2018).

14. Kim, D. H., Kim, K. N., Kim, K. M., Shim, I. B. \& Lee, Y. K. In vitro \& in vivo toxicity of $\mathrm{CoFe}_{2} \mathrm{O}_{4}$ for application magnetic hyperthermia.NSTI-Nanotech, Vol.2, 2007.

15. Montoya-Zamora, J. M., Martínez-de la, A. \& Cruz, E. L. Cuellar, enhanced photocatalytic activity of $\mathrm{BiOl}$ synthesized in presence of EDTA. J TAIWAN INST CHEM E, 75, https://doi.org/10.1016/j.jtice.2017.03.031 (2017). 307 - 16

16. Gheidari, D., Mehrdad, M., Maleki, S. \& Hosseini, S. Synthesis and potent antimicrobial activity of CoFe2O4 nanoparticles under visible light, Heliyon. 6(2020) 05058. https://doi.org/10.1016/j.heliyon.2020.e05058

17. Chang, M. J. et al. Recoverable magnetic CoFe204/BiOl nanofibers for efficient visible light photocatalysis. Physicochem. Eng. Aspects, 562, 127-135 https://doi.org/10.1016/j.colsurfa.2018.11.016 (2019).

\section{Figures}

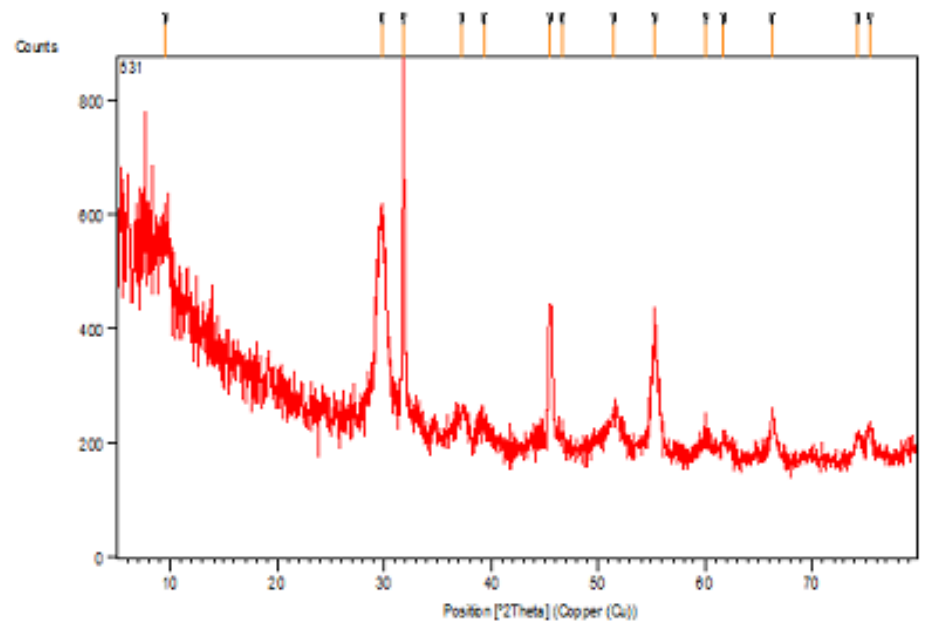

(a)

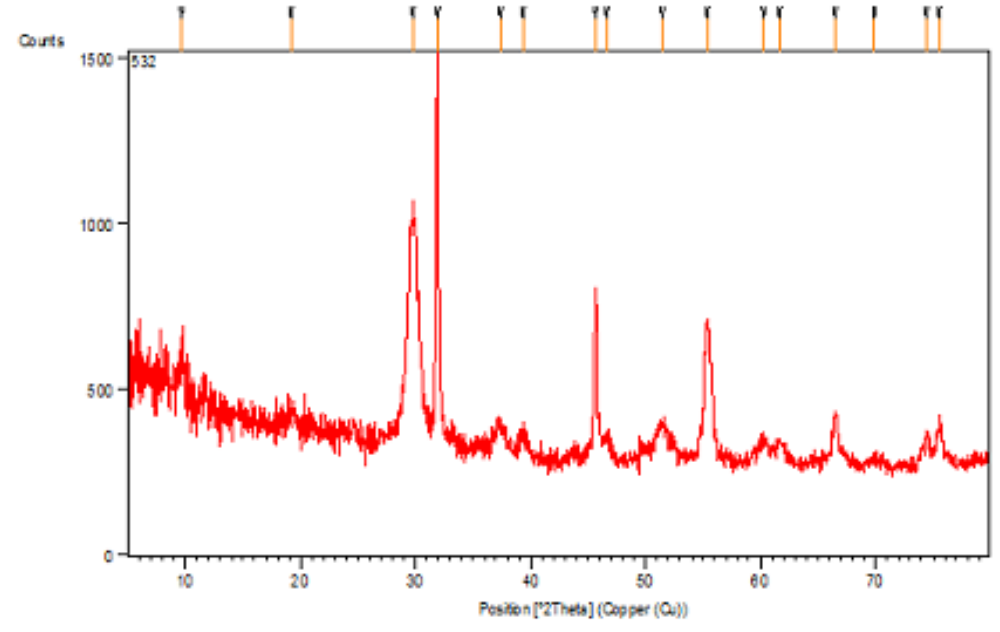

(b)

Figure 1 
X-ray diffraction patterns. (a) BiOI. (b) CFO/BiOI.
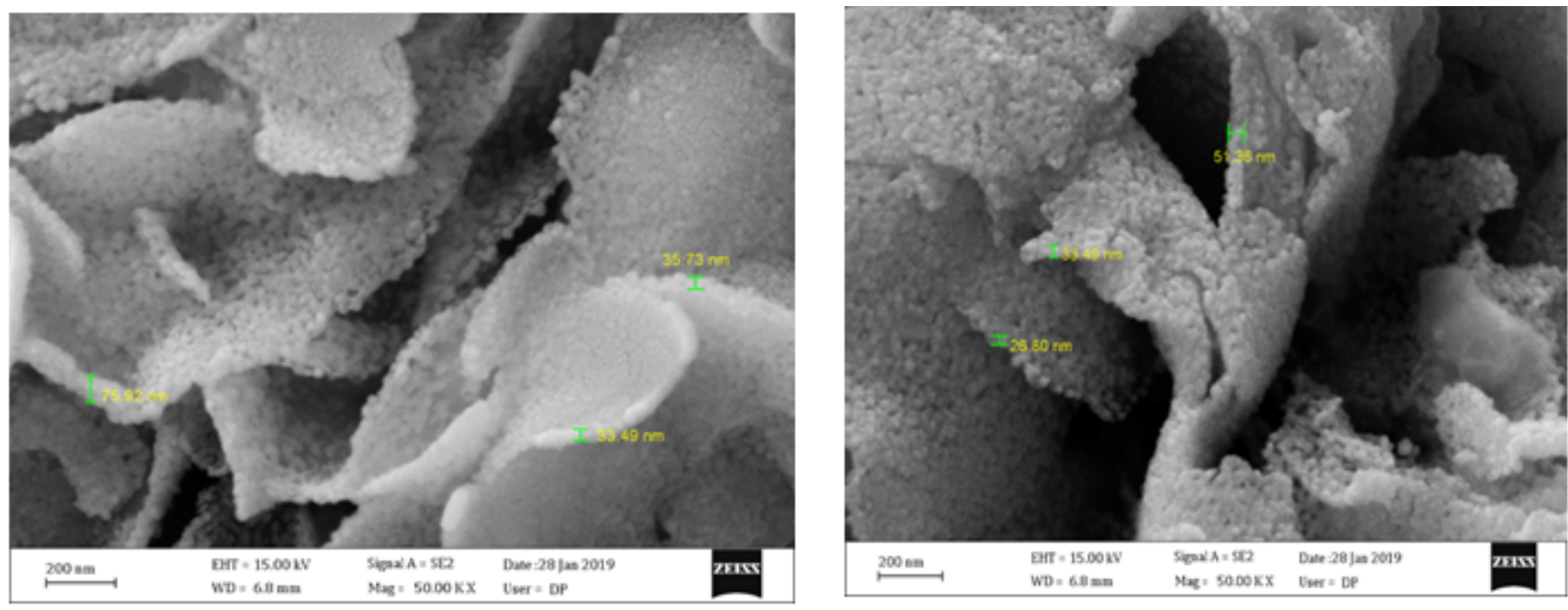

a.

b.

\section{Figure 2}

(a) FE-SEM image of BiOl on a scale of $200 \mathrm{~nm}$. (b) FE-SEM image of CFO/BiOl on a scale of $200 \mathrm{~nm}$.

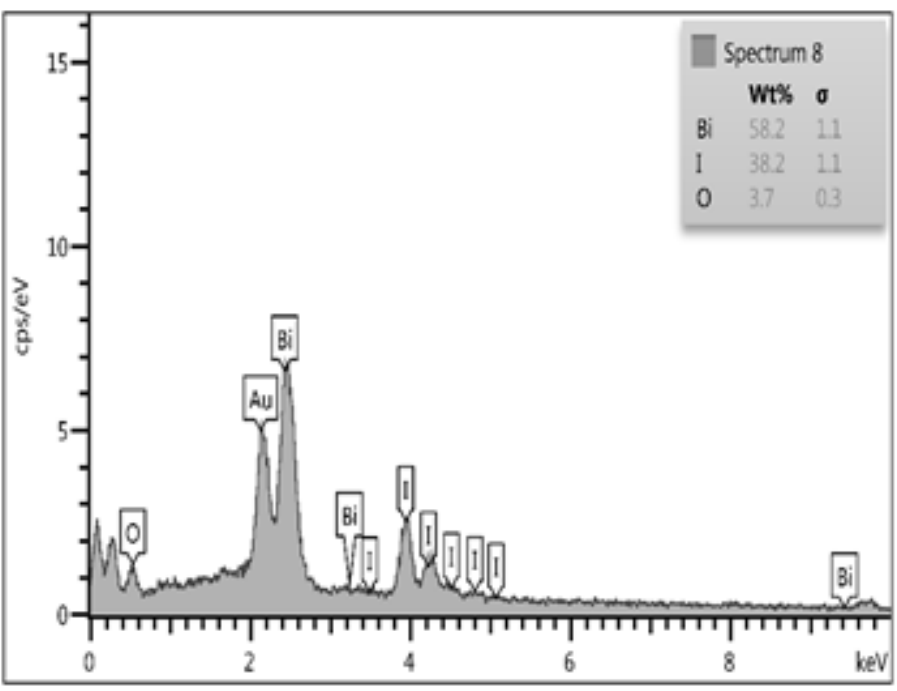

a.

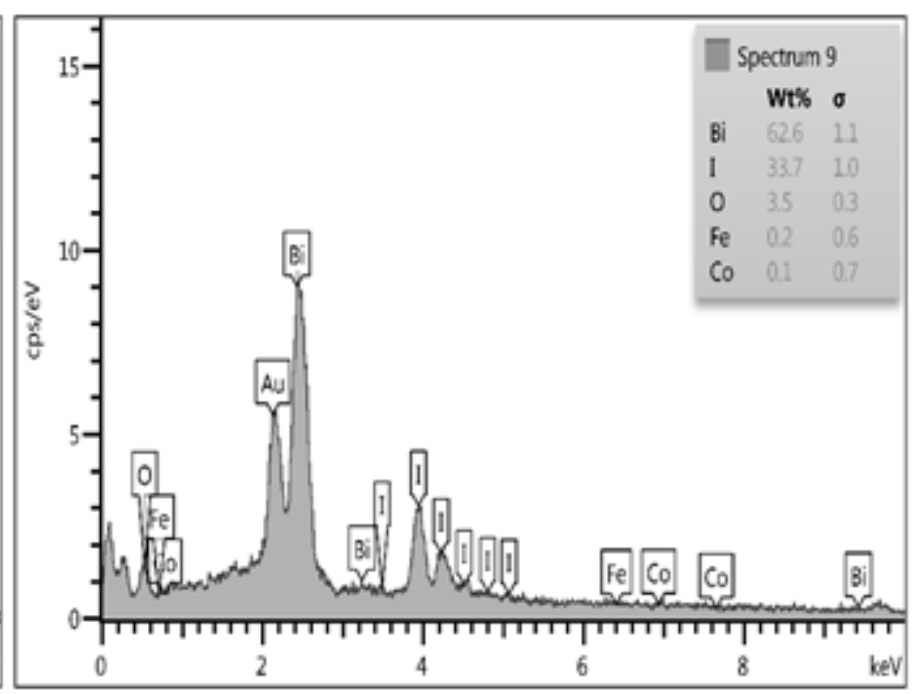

b.

\section{Figure 3}

EDAX spectrum. (a) BiOI. (b) CFO/BiOl with percentage of elements. 

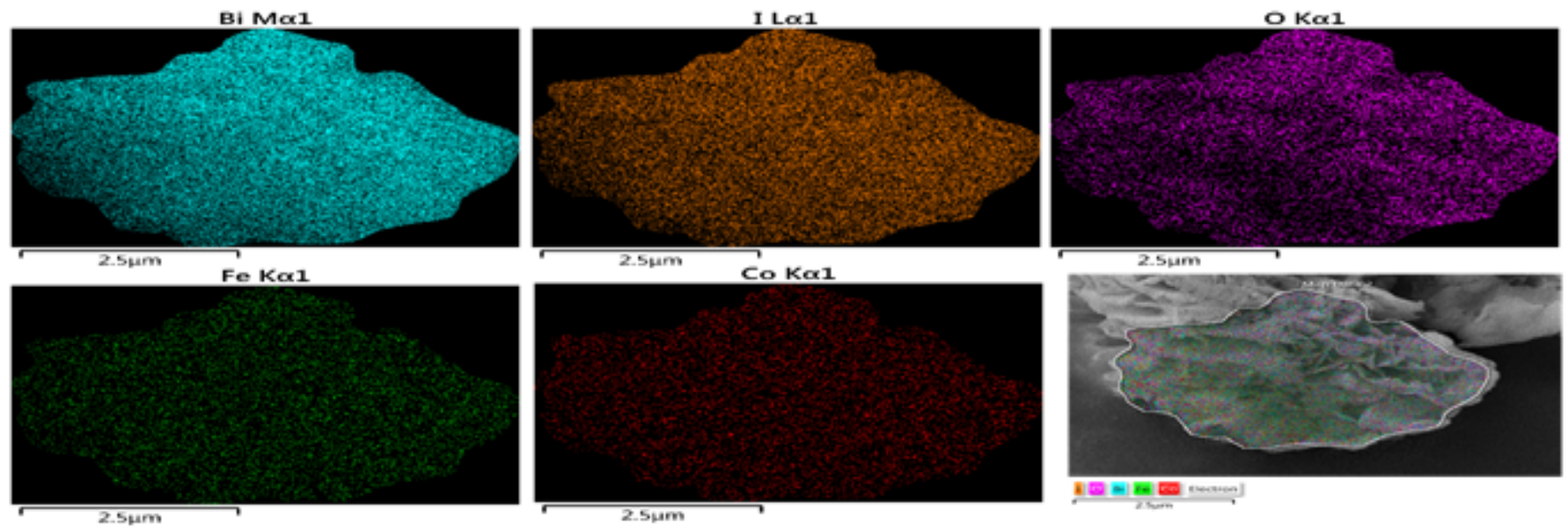

2.5um

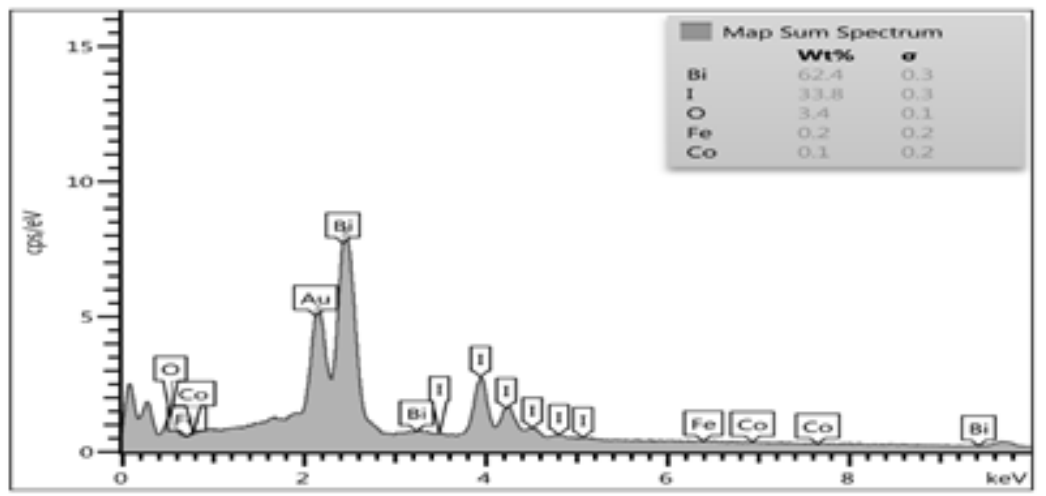

Figure 4

The elemental mapping images and EDAX spectrum of $\mathrm{CFO} / \mathrm{BiO}$ nanocomposites. 